\title{
The Application of Statistics to the Different Areas of Business
}

\author{
Dr. Mcchester Odoh And Dr. Ihedigbo Chinedum E. \\ Department Of Computer Science Michael Opara University Of Agriculture, Umudike, Abia State
}

\section{Introduction}

\subsection{Meaning of statistics}

The word "statistics" has various meanings, all of which are important to us. It can be used to denote numerical data themselves or aggregate obtained from the data e.g. Proportions, averages, that is why we talk of agriculture statistics, industrial statistics, business statistics etc.

Oxford advance learner's dictionary, $6^{\text {th }}$ edition defines statistics as a collection of information shown in numbers. E.g unemployment statistics, crime statistics etc.

Statistics may be also used to designate course of study, which indicates the proper method of collecting, presenting, analyzing and interpretation of numerical data which vary (from time to time, place to place, person to person, material to material etc.)

Based on the above definition of statistics, one could be able to decide logically in human rational that statistics does not draw its conclusion through assumption of incidents; but specifically statistics draws its conclusions systematically through the application of theorems tools, method and techniques used in collection and classification of data, analysis and interpretation of data, derivation and evaluation of the reliability of conclusion reached with the data.

When information is recorded in it's originally collected from whether it be counts or numerical measurements, is referred to as "raw data".

For accuracy, a result is very close or not very far from accuracy, statistical method could be employed for the determination of some variable like prize rate, wages, income rate, the number of population, factories houses, retail shops, birth rates, death rate etc. it is the work of a statistician to professionally employ statistical method in his experiments to give an accurate result with respect to a given sample of a given variable.

Statistics may also be used to designate a course of study, which indicates the proper method of collecting, presenting, analyzing and interpretation of numerical data which vary from time to time, place to place, person to person, material to material etc.

Statistics afford us the knowledge to make future predications; they include the deductive and inductive statistics. Deductive statistics infers that the sample data are only analyzed; summarized and presented without making any inferences about the population while inductive statistics infers to statistical data that is obtained on basis of a sample, selected from a population of units of enquiry, they are used to make valid conclusion about the entire population.

\subsection{Sources Of Data}

Data are classified as either primary or secondary data. Primary data are data that have been collected by the investigator himself or his agent directly from the units of enquiring. The data may or may not have been published. It is in its raw form.

Secondary data are statistical data in its secondary form i.e. the investigator does not initiate himself but which he collects from other published records such as gazettes, books, journals, registers etc.

\subsection{Method Of Data Collection} data.

Methods of data collection of data is distinguished recording to the source whether primary or secondary

Data is collected via secondary method through the use of documentation.

Primary data can be collected through direct observation, questionnaires, personal interviews.

DIRECT OBSERVATION: This method of collection infers that the information is obtained from the units of enquiry by observing them in their natural environment. The participant observer obtains the required information directly by sharing in the activities of the community rather than relying on the reports of information or even on those of the units of enquiry. Direct observation becomes very necessary when the information is notable to supply the required information or is likely to give accurate answers.

BY QUESTIONNAIRES: this refers to a careful formulated set of questions which may be sent to the respondents by post or arrived by field workers or enumerator for their response.

PERSONAL INTERVIEWS; this is usually the method of collection of data in social surveys. Here a set of questions is prepared and administered on the respondents personally by interviews. 
Furthermore, statistics is evident in almost every area of everyday's life. At individual level, decisions are made, using whatever numerical information available. At government level, the science of statistics is applied in virtually every department and laboratory for purposes of analysis and forecasting as well as in the collection and presentation of economic, financial social and demographic data. Similarly, academics and research workers use statistics techniques in their enquires.

In business, the science of statistics has a great number of applications. Decision making by managers requires term to summarize and analyze the various data available to them.

Consequently, statistical terms and concept and their briefly use in business include;

DESCRIPTIVE STATISTICS: Tabular, graphical and numerical methods are used to summarize data sets. These can be used for data set which relates to entire population or samples.

INFERENTIAL STATISTICS: techniques employed in making estimates and drawing conclusions about the characteristics of a statistics population using results from a sample data set.

POPULATION: the set of items which are of interest in a particular study.

SAMPLE: a portion of the population selected so as to represent the whole population.

CONSULS: the collection of information about every member of a statistical population.

PARAMETER: A numerous value, such as an average, used as a summary measure for an entire population.

STATISTIC: A characteristic which takes on values for different members of the population or sample data sets. E.g. weight, monthly sales, sex of employs.

\subsection{Definition Of Business}

\section{Business: Definition And Meaning}

In this chapter, it is believed that the complexity of the concept of business will be understood more by the reader from a general to a more specific use of term. Many scholars in business management gave their individual definitions of business, but we are going to concentrate on few definitions and in the same respect it is seemed necessary to give series of definitions by different scholars so that the concept of business will register consciously in the everyday life of the reader. With the prior knowledge of business by the reader, he can then understand the application of statistics to business in the next chapter.

According to Horby (1995:151) business can be defined as "the activity of making, buying, selling or supplying things for money; commerce or trade.

Onuaha (1991:78) defined business as a set of activities in which persons working alone or in group try to produce and distribute the goods which are important to the comfort and general well-being of people and for the benefit of the society in general at a profit.

In the view of Enudu (2004:2) it is defined as "any activity which is profit oriented, legal and directed at satisfying the needs of the general public.

Fredrick Hooper (1961:150) has given a definition of business as a "whole complex field of commerce and industry the basic industries, and the network of ancillary services, distribution, banking, insurance, transport, and so on, which serve and interpenetrate the world of business as a whole. Based on the foregoing, it is note worthy that both the person living in the village and the person living in the city in their daily endeavors enters into business transactions for the food eats, the clothe, the cars and other commodities needed for satisfying his wants. In other words, every person is touched by business daily. To facilitate better understanding of definition of business, lets us consider these questions:-

1) Is every money-making activity a business?

2) If yes, what about gambling armed robbery, advance fee fraud (419), etc.

3) Is a farmer in business?

4) What is the difference between a person who works for himself and another person who does the same work for another person?

5) Is an inventor a business man

A business has an objective and to actualize such objective, it has to streamline it activities and strategies to achieve these objectives. For most businesses, the maximization of profit after taxation is the prime objective. The prospect of business profit is what encourages people to open and expand business. Today business produces varieties of everyday goods and services and employs most working people in Nigeria. Businesses also serve as a support for the government with payment of taxes and other charges. A major determinant of business in the kind of economic system that characterized the country. An economic system allocates a nation's resources among its citizens. Economic system differ in who owns and control these resources i.e. factors of production. 


\subsection{Categories Of Business}

A business is characterized based on its output. i.e. service oriented businesses and goods oriented businesses. Some businesses perform service functions that have an intangible feature. E.g. Barber shop, the service of ups, DW, physical etc. Goods oriented businesses seek to provide tangible and physical product to consumers/customers. This category of business follows a channel of distribution in order to reach the final consumer e.g. Omo Table, Mobile phone etc.

In all, business needs the series of factors of production in order to obtain its objectives and survival rate .i.e. every category of business needs capital to commence the business, and to keep the business operating and growing e.g. shell's annual drilling costs alone amount into trillions of naira; natural resources such as land, water, mineral deposit, tax etc. for example, mobile oil producing company makes use of a wide variety of natural resources mainly crude oil to remain in business and land for it pipelines and refineries; service-oriented business need land to site company buildings or premises; labour otherwise called human resources, represent the people who work for a company and it is the mental (white collar jobs) and physical capabilities (blue collar jobs) of people i.e. employees; entrepreneurs who accept the opportunities and risk involved in creating and operating business. They are the people who start new businesses and who make the decisions that allow small business to grow into larger ones. E.g. Dangote Aliko, Adenuya Mike etc.

\subsection{Types Of Business}

All business owners decide which form of legal organisation suits them whether it is the most popular business everywhere. However, sole proprietorship may be as large as a steel mill or small as a kiosk.

Partnership which is a business with two or more owners who share in the operation of the firm and in financial responsibility for the firm's debts.

Corporation are businesses considered by law to be a legal entity separate from its owners with many of the legal rights and privileges of a person; a form of business organization in which the liability of the owners is limited to their investment in the firm.

\subsection{Scope}

\section{Areas Of Business}

Statistics is a powerful tool for analysis numerical data. Its application is necessary in different professions of business like sciences, Engineering, Education and Administration etc. in the physical sciences, results obtained from statistical analysis of data may help decide whether or not experimental results should be added in the body of the existing knowledge. In the biomedical science, statistical outcome of an experiment may be a function for a need for intervening action. In the same respect, a physical uses statistic to assess the effectiveness of a particular treatment. In determining the potency of drugs, the pharmacist employs statistical method in his evaluation.

In the field of social sciences, such as Psychology, Sociology, Economics, Anthropology etc, numerical data on individuals and groups are often used to develop theories and models of behaviour. In the fields of Engineering, Business and Education, statistical is used in planning, policy formations and setting goals and standards. The school administrator may use statistics information to reshape academic curriculum. The civil Engineer uses statistics to determine properties of various metals and materials to predict sales, design and improve products, produce goods and provide services more efficiently.

Summarily, business managers in the various fields/aspects of business make good use of statistical knowledge in order to excel in their various discipline/endeavours.

\subsection{Introduction}

\section{Application Of Statistics To The Areas Of Business}

For business in a broad sense, statistics has a lot to do in business manufactures on the possible techniques and future of a product. It is important for managers to understand the relevance of statistical methods, to be able to interpret statistical results. The quality of decision depends on the accuracy of the information or data on which it is based. The fact finding/collection and statistical methodology is to help managers make good decisions in the face of uncertainty. Managers employ statistics in planning, in establishing policies, in setting standards, in fore casting business activities and in control.

The knowledge of data collection would assist business managers both in internal and external areas. The source of internal data of an enterprise arises from its daily operation and these facilitate their decisions making process. These data are gotten based on different areas of interest like production unit, selling and financial activities fall under secondary internal data. External data refer to the outside environment of the business such as market, government, competitors, suppliers, the economy as a whole etc. business managers need information on the current government policy based on the price level whether it is maximised or 
minimised, regulations or laws invoke, ministries declarations and other government agencies. External primary data could be in form of surveys, questionnaires, opinion polls etc.

Statistical Knowledge in business, help business managers make use of statistical decision analysis in order to promote their business. In the face of bleak uncertainties, managers are faced with an important point in business to make decision. The decision maker would sit down, close eyes and think about the problem on a basis of combination of experience, hunch and judgement. Alternatively, the decision-maker can approach the problem rather differently and systematically sort out various elements contained in the decision and the use certain decision rules to help him decide on what to do.

\subsection{Sampling Design}

Based on the above, we have seen how relevant data or information could be derived through personal interviews, mail questionnaires and others. How do we design a sample? Or how is the plan made to identify the mind of people, the type of retail shops, or the schools we wish to research or investigate? Most often our emphasis mostly lies on how statistical procedures are employed to solve problem of our interest. Managers in business organisation employ statistical methods to find information which helps them to manage profitably, by planning well and knowing their target, for example you would like to know the market demand for soap Y, Bread X, or Razor Blade Z you may like to know who your competitors are, their strength and weaknesses. Adherence to these statistical methods of predicting uncertainties will help you make better decisions, help you (the business managers) to minimize costly errors. One other thing noteworthy in statistics in the proper arrangement of numbers, their classification and summarization rather than mass of figures, numbers and formula

\subsection{Descriptive Techniques}

These involve tabular and graphical presentations of data, methods for describing sets of data by single summary measures of central location and variability, and the derivation of index numbers.

Tabular and graphical methods of arranging and presenting statistical data. The purpose of these methods is, of course to condense the information from a mass of figures (raw data) into a form which provide an informative summary and readily convey the essential features of the data, this is important for managers who only see and interpret result consider, for example the data shown in Table 1. This shows that beer sales in each of the 60 public houses owned by Bitter Beer Brewery for January 1991.

Table 1 Beer sales in public houses

\begin{tabular}{|l|l|l|l|l|l|l|l|l|l|l|}
\hline 48 & 71 & 52 & 53 & 36 & 41 & 69 & 58 & 47 & 60 & 53 \\
\hline 29 & 41 & 72 & 81 & 37 & 43 & 58 & 68 & 42 & 73 & 62 \\
\hline 59 & 44 & 51 & 53 & 47 & 66 & 59 & 52 & 34 & 49 & 73 \\
\hline 29 & 47 & 16 & 39 & 58 & 43 & 29 & 46 & 52 & 38 & 46 \\
\hline 80 & 58 & 51 & 67 & 54 & 57 & 58 & 63 & 49 & 40 & 54 \\
\hline 61 & 58 & 66 & 47 & 50 & & & & & & \\
\hline
\end{tabular}

A simple way to condense such data is to draw up a tabular summary in the form of a frequency distribution as shown in table 2 in which the variable (beer sales) has been grouped in order to reduce it to a manageable form.

Table 2 Frequency Distribution of Beer sales

\begin{tabular}{|ll|l|l|}
\hline No of Barrels & \multicolumn{2}{l|}{ No of Public Houses (F) } & Relative \\
\hline Frequency (\%) & \multicolumn{2}{l|}{} \\
\hline 10 & -19 & 1 & 1.7 \\
\hline 20 & -29 & 3 & 5.0 \\
\hline 30 & -39 & 5 & 8.3 \\
\hline 40 & -44 & 16 & 26.7 \\
\hline 50 & -59 & 20 & 33.3 \\
\hline 60 & -69 & 9 & 15.0 \\
\hline 70 & -79 & 4 & 6.7 \\
\hline 80 & -89 & 2 & 3.3 \\
\hline & 50 & 100.0 \\
\hline
\end{tabular}

This tabular representation makes it easier for a business manager to fully assess and know the implication of the business.

Graphical representations which include line graphs, line charts, bar charts, Histograms, Frequency polygons, Cumulative frequency curves (0 gives), Pie charts, Graphs. Business movements overtime are often of special interest in line graphs in that they highlight trends line charts are instructive given that in a survey by a company, the number of defective goods returned to each of its 60 distributors makes it easier to ascertain where the variable (number of defective goods) is discrete and the data is ungroup. Whereas, for grouped data, bar 
charts or history are appropriate, depending on whether the variable is discrete or continuous respectively. Bar charts are simple extension of the idea of a line chart, using bars to replace lines. Bar charts are also particularly useful when the variable of interest can be subdivided into a number of components which are to be illustrating of the same time.

Histogram being similar to bar charts except for that there are no gaps between the bars. It can be used to cases involving either discrete or continues data, unlike bar charts which apply only to the former. Frequency polygons provide a useful alternative to the histogram, particularly when one wants to compare two distributions on the same diagram. To try to do this with histogram would mean that some parts would over-lap and it would be difficult to distinguish one histogram from the other.

Cumulative frequency curves (0gives) show the distribution of categories 1 data say weights of male passengers on a cumulative basis. The data presented on this form are referred to as a cumulative frequency distribution and the graphical representative as a cumulative frequency curve (0give). For instance

Table 3: Distribution of weight of male passengers

\begin{tabular}{|l|l|}
\hline Weight (kilos) & Cumulative Frequency \\
\hline Less than 50 & 0 \\
\hline Less than 60 & 28 \\
\hline Less than 70 & 96 \\
\hline Less than 80 & 188 \\
\hline Less than 90 & 250 \\
\hline Less than 100 & 272 \\
\hline
\end{tabular}

Measure of location or central tendency consist of Arithmetic Mean, Media, Mode and Geometric mean. Arithmetic mean is the most commonly used and is simply known as average or the mean. It is obtained simply by se Adding the value of all the items in a data set (denoted by X1, X2, Xn) and dividing by the number of items (denoted by $\mathrm{n}$ ).

Thus Arithmetic mean $=X=\frac{\sum \times 1}{n}$

Or

Weighted Arithmetic mean $=\mathrm{X}=\frac{\Sigma_{\mathrm{f} 1 \mathrm{x} 1}}{\Sigma_{\mathrm{f} 1}}$

$$
\frac{\mathrm{f} 1 \mathrm{x} 1+\mathrm{f} 2 \mathrm{x} 2+\cdots+\mathrm{fnxn}}{\mathrm{F} 1+\mathrm{f} 2+\cdots+\mathrm{fn}}
$$

Median, is the name suggest, is the value in the middle of the state set when the observations are arranged in order from smallest to biggest, e.g.

$8,5,4,9,5,11,6,5,8$

Rearranged them, it would be

$4,5,5,5,6,8,8,9,11$

Median

Mode, which is simply the value that occurs the most often e.g. 8,5,4,9,5,11,6,5,8

The mode is 5 because it occurs three times

Geometric mean may be used when it is desired to produce an average of percentage charges. This is particularly, relevant in business situations where the manager may be interested in measuring the rate of increase in sales, costs, price etc. the Geometric mean is simply the nth root of the product of $\mathrm{n}$ items. Thus;

Geometric mean $=\mathrm{g}=\sqrt[\mathrm{n}]{\mathrm{X} 1 \times \mathrm{X} 2 \times \mathrm{X} 3 \times \ldots \ldots \ldots \times \mathrm{Xn}}$

Measures of dispersion also refer to the range, modified ranges, mean derivation, standard derivation, variance, coefficient of variation.

\subsection{Analytical Techniques In Business}

These represent the core of statistical theory. There are large number of techniques particularly the concepts of probability and probability distributions lie at the heart of statistical analysis and, in particular statistical inference and decision making. The study of probability involves assessing, in the contest of uncertainty, the likelihood that something will occur by change e.g. that a machine will breakdown, goods will be defective, or the wrong decision will be arrived at. In statistical inference we typically wish to make some decision about population parameters. Given information available only from a sample of data draw from the population. There are two main areas of the subject; estimation of the population parameters and testing hypothesis about them.

Another important aspect of data analysis is the measurement of relationship between variables. This topic involves, on the one hand, statistical tests of association between actual and assumed distributions of data as well as tests of independence of categorized data. On the other hand, we are able to determine the nature of 
relationships and the degree of association between observations on the variables, using regression and correlation analysis.

\subsection{Probability For Managers}

Probability is another statistical concept that is of great importance to the manger. The manager's decisions are in probabilistic terms. Thus, there is always an element of uncertainly on most of the decisions of managers undertake. If a manager makes the outcome is certain, the puzzle is said to be deterministic. For the manger, it spears as if he is doing a random selection. He cannot say for sure the content of his venture due to some chance of elements that spoil his expectations.

Probability is a brother to may-be or may-be-not type of statement. If the manager is perfectly sure of his outcome, he is said to be certainty operator and certainly denotes a probability of one (1) i.e. 1.00. A situation of perfect uncertainty has a probability of 0.00 (zero). All the decisions where the manager is neither perfectly unsure nor perfectly sure have probabilities of valve between 1 and 0 . Probability cannot be greater than 1 and there is no negative probability. The probability of any management event stands between one and zero.

Probability of occurrence of event for example, the probability of getting an event is by computing the maximum number of ways through which an event can occur compared with the maximum number of ways all events in the experiment can occur. This ration is called probity. For example, if a coin of two tossed, the chance of getting event $1 / 2=0.5$. A tie of six sides is tossed and the probability of getting the side bearing four (4) dots is simply $1 / 6$

$=0.17$

When the manager says that he is excepting a sales volume of 20,000 blocks in one week, he is making statement render probability. This statement is necessitated based on the past event. He can make less than 20,000 or a little bit more than 20,000. Finally, probability provides the manager with a substitute for certainty. "A" probability concept called conditional probability is a tool that describes the new probability corresponding to same event "B" after it is known that some other event A has occurred. Symbolically, it is written P (B/A). the vertical line (I) dose not mean division instead; it is read "give" and in the probability of B given that A happened.

The probability of the event B given the condition that the event A had occurred, called a conditional probability is defined as:

$\mathrm{P}(\mathrm{B} / \mathrm{A})=\frac{\mathrm{P}(\mathrm{BnA})}{\mathrm{P}(\mathrm{A})}=\frac{\mathrm{P}(\mathrm{AnB})}{\mathrm{P}(\mathrm{A})}$

Here, we assume that $\mathrm{P}(\mathrm{A})$ is greater than zero. On the other hand, the conditional probability that $\mathrm{A}$ will occur given that $\mathrm{B}$ has occurred, is written as $\mathrm{P}(\mathrm{A} / \mathrm{B})$ and is defined to be:

$\mathrm{P}(\mathrm{A} / \mathrm{B})=\frac{\mathrm{P}(\mathrm{AnB})}{\mathrm{P}(\mathrm{B})}=\frac{\mathrm{P}(\mathrm{BnA})}{\mathrm{P}(\mathrm{B})}$

Here, we assume also that $P(B)$ is greater than zero.

Since $P\left(\frac{A}{B}\right)=\frac{P(A n B)}{P(B)}=P(B) P\left(\frac{A}{B}\right)=P(A n B)$.

This new equation is often referred to as the general multiplication rule for probabilities. There are two ways to calculate $\mathrm{P}(\mathrm{AB})$ : Given any two events $\mathrm{A}$ and $\mathrm{B}$.

$\mathrm{P}(\mathrm{A} \times \mathrm{B})=\mathrm{P}(\mathrm{A}) \mathrm{P}(\mathrm{B} / \mathrm{A})$

$\mathrm{P}(\mathrm{A} \times \mathrm{B})=\mathrm{P}(\mathrm{B}) \mathrm{P}(\mathrm{A} / \mathrm{B})$

Two events $A$ and $B$ are independent if and only if

1. $\quad \mathrm{P}(\mathrm{A} / \mathrm{B})=\mathrm{P}(\mathrm{A})$

2. $\quad \mathrm{P}(\mathrm{B} / \mathrm{A})=\mathrm{P}(\mathrm{B})$

Here, we assume that each of $\mathrm{P}(\mathrm{A})$ and $\mathrm{P}(\mathrm{B})$ is greater than zero. When we say condition is (1) and (2) are equivalent, we mean that condition (1) holds if an oly if conditions (2) holds.

As an illustration, a research firm carried out a test on a soft drink as it regards its taste. 1000 consumers of a soft drink were asked to choose between two different types of the soft drink they prefer. Each of the consumers was also asked whether they prefer their drinks sweet or very sweet. The research firm unfortunately lost some of the survey information due to a firm outbreak that occurred last year. However, some information was recovered. The recovered survey information includes:

1. 68 percent of the consumers preferred type 1 drinks to type 2 drink.

2. 60 percent of the consumers preferred their drinks sweet (rather than very sweet)

3. 80 percent of the consumers who said that they liked their drinks "sweet" preferred type 1 drink to type 2 drink 
The firm is new now facing the challenge of recovering other missing information. To recover all of the lost survey information, consider randomly selecting one of the 1,000 survey participants, and defined the following events.

$\mathrm{T}_{1}$ the randomly selected consumer prefers types drink.

$\mathrm{T}_{2}$ the randomly selected consumer prefers sweet drinks.

$\mathrm{S}$ the randomly selected consumer prefers sweet drinks.

$\mathrm{V}$ the randomly selected consumer prefers very sweet drinks.

From the survey information that remains

$$
\begin{aligned}
& \text { 1. } \text { Says } \mathrm{P}(\mathrm{T},)=\frac{68 \% \text { of } 1000}{1000}=0.68 \\
& \text { 2. } \\
& \text { 3. }
\end{aligned}
$$

In order to recover all of the lost survey information, we find $\mathrm{P}(\mathrm{T} * \mathrm{~S})$, Recalling the general multiplication rule $\mathrm{P}(\mathrm{T}, * \mathrm{~S})=\mathrm{P}(\mathrm{T}) \mathrm{P}(\mathrm{S} / \mathrm{T})=,\mathrm{P}(\mathrm{S}) \mathrm{P}(\mathrm{T} / \mathrm{S})$

$\mathrm{P}(\mathrm{T}, * \mathrm{~S})=\mathrm{P}(\mathrm{S}) \mathrm{P}(\mathrm{T}, / \mathrm{S})$

$=(0.6)(0.8)$

$=0.48$

This implies that 0.48 of the 1000 consumers preferred type 1 drink and preferred their drinks sweet. i.e. 480 consumer preferred sweet type 1 drink. Since 680 consumers preferred type 1 drink, and 600 consumers preferred sweet type 1 drink, we can summarize the numbers of consumers corresponding to the events $T_{1}, T_{2}$, $\mathrm{S}, \mathrm{V}$ and $\mathrm{T} * \mathrm{~S}$.

\section{Conclusion}

This chapter ultimately universe the importance of statistics to business. The chapter carefully selected some vital that show the inevitability of statistics the managerial profession. It is hoped that by the end of this chapter that the reader will authoritatively say something that is worth treasured pertaining to the application of statistics to business.

From the foregoing, if ultimately can unveiled the importance of statistic to business. The chapters have carefully outline some vital issues/concepts that timely shows the inevitability of statistics will help us to know the implication of statistics in business and the consequences of implication.

\section{References}

[1]. Enudu, O. T. (2004). Introduction to Business Management: Johnkens and Willy Publications, Enugu.

[2]. Oyeka ,C .A. (2002), Elements of Applied Statistics, Cidac Publications, Enugu

[3]. Unamka .P.C. and Ewurum .U.J.F. (1995), Business Administration; Precision Printers and Publishers

[4]. Fleming and Nelli, A. (1991). The Essence of Statistics for Business; Prentice Hall.

[5]. Edwin, W. (1986). A Guide to Business Performance Measurement, Macmillan.

[6]. Peter ,M. (1972) Risk in Business Decision Longman. 